\title{
Thirty Years of Systemic Practice and Action Research
}

\author{
Robert L. Flood ${ }^{1}$
}

Published online: 27 March 2017

(C) Springer Science+Business Media New York 2017

Opening Words The speed at which time passes seems to be ever increasing as I get older. Likewise, reflecting back on life consumes more time than planning for the future. I am reaching the retirement zone at 62 years of age and many of my research heroes from the $\mathrm{PhD}$ days have passed on. Over time I learnt that only one thing never changes and that is that everything is always changing, which in turn is true for Systemic Practice and Action Research.

The journal was launched in 1988 with four issues a year under the name Systems Practice. The aims and scope in short were to publish articles that employ systems ideas for the betterment of people's lives. I was the founding editor, age 33, working at the Department of Systems Science at the City University in London, UK. The publisher was Plenum in New York, followed by Plenum-Kluwer, and now Springer. The journal lived through the turbulent times of the publishing industry in the 1990s into the new millennium and survived when many other journals did not. The publisher's editors have given me tremendous support over the years. With Springer, this journal is in the safe hands of a top international publishing house.

In the 1990s, the journal's name was changed to Systemic Practice and Action Research. Why did a successful journal change its name? The editorial team recognised that systems thinking and systems practice had matured considerably, with the emergence of soft systems thinking and critical systems thinking, and that the guiding principles were systemic and shared with action research. Accordingly, there were some historic mini conferences between systems thinkers and action researchers with the set purpose of exploring the relationship between the 'two disciplines'. I remember two in particular, both during my professorship at Hull University, UK. The first brought together our Centre for Systems Studies with Peter Reason's research team from Bath University. The second was organised by Morten Levin from the Norwegian University of Science and Technology.

As a result of these meetings I was inspired to write the article, 'The Relationship of Systems Thinking to Action Research.' It was published in the Handbook of Action Research

Robert L. Flood

editor.spar@gmail.com

1 Norwegian University of Science and Technology, Trondheim, Norway 
edited by Peter Reason and Hilary Bradbury (Sage, London, 2000). A revised version was published in Systemic Practice and Action Research 23: 269-284 (2010). I am so pleased that this article has been and still is widely cited.

Recently, I looked back over the 30 years of articles published in the journal, in preparation for a talk at the Norwegian University of Science and Technology. I was reminded that the journal has matured considerably. Here is summary review.

1980s Not surprisingly, in the first few years of the journal there was much emphasis on systems modelling and simulation, and systems theory including cybernetics, complexity, entropy and autopoiesis. The rise of soft systems thinking is well documented and the first 'hints' of critical systems thinking can be found. The main topics in practice involved the environment, energy, farming, and enterprises. The 'big names' that dominated at the time included Russel Ackoff, Stafford Beer, and C. West Churchman. I was privileged to meet all three of these brilliant thinkers, and I feel sad that all three have passed on. I do hope that new generations of systems thinkers take the time to engage with their writings.

1990s Soft systems thinking was dominant in the 1990s and Peter Checkland was very much at the forefront of research and practice. Like us, Peter recognised an important relationship between systemic thinking and action research. However, the new decade brought with it new research and practices, and new researchers and practitioners. In this decade, the rise of critical systems thinking is evident with greater coverage of issues like power, ideology, and emancipation. A whole new topic emerged that investigated complementarity between methodologies. This was also an important decade for my research, with particularly productive working relationships with Mike Jackson and Norma Romm. I do not forget their contributions to the journal, in both articles and intellect, neither do I forget their friendship. The main additional topics in practice in the 1990s included information systems, quality management, and importantly disability, community projects, and southern action research. In the early years of the journal, authors tended to be mainly from Europe and North America, but in the 1990s authorship increasingly became transglobal.

Furthermore, the connection with action research strengthened. This is marked by two important publications in this journal. The first is a key article by Morten Levin in 1994, 'Action Research and Critical Systems Thinking - two icons carved out of the same stone,' Systems Practice 7: 25-41 (1994). The second is a special issue on action research in February 1998.

From 2000 The journal was publishing six times a year by the new millenium. There was so much more to report. The input from action researchers increased. Additional themes emerged such as wholeness and spirituality, and eastern philosophies. The areas of practice were unbounded.

In 1997, I left full-time employment in academia and have since made my living in various ways. Systemic Practice and Action Research remained central to my life, though. I have been very lucky in my career to attain a full professorship at 33 years old and this gave me a wonderful opportunity to explore the systems idea and its relevance to the modern-day world. At the same time, I launched the journal Systems Practice with Plenum and in so doing found myself in rather an influential role. I steered the journal toward new and challenging social issues and created a platform for critical systems thinking. I also had the opportunity to publish several books arguing for a complementary approach to systems and action research methodologies founded on principles of critical systems thinking.

I have been incredibly lucky. So, from 2000, I made a decision to invest much of my time and editorial efforts into the encouragement and support of people, organisations, and 
communities that lack a voice, but have important things to say to the journal's readership and to the wider world. This involved a lot more work for the editorial team, but it has been worth it. The articles published over the last 15 years are a testament to the journal's achievements. Systemic Practice and Action Research works by its principles in so far as it is practically possible. I am confident that it will continue to do so.

End Words I wish to make special mention of Simon Bell from the Open University, UK. Simon was Deputy Editor of the journal for many years and only recently stepped down from this post. The journal benefited hugely from Simon's creativity and intellect, which he offered with great generosity to the journal, without ever compromising his ethical principles. I am sure that many authors and readers share with me a big thank you to Simon. I also want to mention Morten Levin who is an inspiration to me and, more than anyone else, helped to build momentum in the rich engagement of systemic thinking and action research that now characterises this journal.

So, times are changing. It is approaching the time that I hand on this journal to younger generations to make of it what they will. In preparation, you will note some changes to the editorial team over the coming few years. To start with, you will see on the journal's website the addition of two Deputy Editors from the action research hub at the Norwegian University of Science and Technology in Trondheim, Norway. I welcome them both: Hanne O. Finnestrand and Ola Edvin Vie.

Now we enter a new era for Systemic Practice and Action Research, a journal that has become so much a part of my life. Like a child leaving home, the journal will move on and find new friends in a new life, but surely will never lose touch with its pedigree and older friends. 